\title{
APONTAMENTOS PARA UMA CARTOGRAFIA DA CARTOGRAFIA GEOGRÁFICA BRASILEIRA
}

\section{Indications for a Cartography of the Geographic Cartography in Brazil}

Prof $^{\mathrm{a}}$. Dra . Gisele Girardi

Universidade Federal do Espírito Santo

Av. Fernando Ferrari, 514, Goiabeiras, CEP: 29060-900 - Vitoria, ES - Brasil Tel/Fax: (+55 27)33357628 / 33352517 - gisele.girardi@pq.cnpq.br

\section{$a \boldsymbol{a}_{a a}$}

\begin{abstract}
Resumo
Este artigo busca apresentar um panorama da pesquisa em e com cartografia no âmbito da pesquisa geográfica no Brasil a partir de indicadores institucionais, ou seja, dos dados de grupos de pesquisa do CNPq e teses do banco da Capes. Para análise dos dados foi elaborado um conjunto de questões: Que áreas abrigam na atualidade a pesquisa em cartografia no Brasil? Qual é o lugar da ciência geográfica neste contexto? Qual é a situação atual da pesquisa em cartografia no campo da geografia acadêmica? Quais são suas principais tendências?As ênfases temáticas dos grupos e teses citados foram sistematizadas nos blocos "Aplicação Geotecnológica" "Aplicação em Ensino de Geografia" e "Abordagens Teórico-Metodológicas", que foram analisados a partir de perspectivas epistemológicas e práticas. Foram avaliados os campos hegemônicos e os de desestabilização, identificando estes últimos como a potência de contribuição da Cartografia Geográfica à ciência geográfica.
\end{abstract}

Palavras-chave: Cartografia, Pesquisa em Geografia, Cartografia Geográfica

\begin{abstract}
This paper presents an overview of research about and with cartography on the context of geographical research in Brazil from institutional indicators, i.e., data of research's groups of CNPq and thesis database of CAPES. For data analysis was prepared a set of questions: Currently, in Brazil, in which knowledge's areas are the research in cartography? What is the place of geographic science in this context? What is the current state of research in cartography in the field of academic geography? What are the main trends? The thematic emphases of the mentioned groups and theses were systematized in the follow blocks: "Geotechnologic Application", "Application in Teaching Geography" and "Theoretical and Methodological Approaches" that were analyzed from epistemological perspectives and practices. Hegemonic fields and destabilization fields were evaluated and the last one was identified as the power of Geographic Cartography's contribution to geographical science.
\end{abstract}

Key-words: Cartography, Research in Geography,Geographic Cartography

\section{Resumen}

Este artículo busca presentar un panorama sobre la investigación en y con cartografía en el ámbito de la investigación geográfica en Brasil a partir de los indicadores institucionales, o sea, de los datos de grupos de investigación del CNPq y tesis del banco de la Capes. Para análisis de los datos fue elaborado un conjunto de cuestiones: ¿Qué áreas abrigan en la actualidad la investigación en cartografía en Brasil? ¿Cuál es el lugar de la ciencia geográfica en este contexto? ¿Cuál es la situación actual de la investigación en cartografía en el campo de la Geografía académica? ¿Cuáles son sus principales tendencias? Los énfasis temáticos de los grupos y tesis citados fueron sistematizadas en bloques "Aplicación Geotecnológica" "Aplicación en Enseñanza de Geografía” y “Abordajes Teórico-Metodológicas”, que fueron analizados a partir de perspectivas epistemológicas y prácticas. Fueron evaluados los campos hegemónicos y los de desestabilización, identificando estos últimos como la potencia de la contribución de la Cartografía Geográfica a la ciencia geográfica.

Palabras-Clave: Cartografía, Investigación en Geografía, Cartografía Geográfica.

\section{aaCaa}




\section{INTRODUÇÃO}

Nossa intenção neste artigo é apresentar algumas contribuições para a análise da pesquisa em cartografia no âmbito da pesquisa geográfica no Brasil. Sua escrita foi motivada por solicitação da Comissão Organizadora do XI Encontro Nacional da Associação Nacional de Pós-Graduação em Geografia para abordar o estado da arte na temática "cartografias, representações e análise espacial”.

Alguns esclarecimentos iniciais são necessários para justificar a abordagem que adotamos para a construção deste texto. O primeiro é que elegemos a cartografia como linha central para a análise, entendendo esta como potente para abordar os outros dois termos. É certo lugar comum nos discursos sobre a cartografia a sua definição como representação do espaço, o que suscita um campo bastante grande de reflexões e questionamentos vinculados à própria polissemia científica para o termo representação.

Mesmo sem aprofundar tal questão neste momento, o que temos como fundamento da maior parte destes discursos é a noção da representação como re-apresentação, ou seja, há um "antes" ("o" espaço geográfico) à disposição para ser observado e ter alguns de seus elementos selecionados para tradução gráfica num suporte qualquer. Bastaria, portanto, saber selecionar os elementos e ter competência em linguagem cartográfica para elaborar mapas.

Este pensamento sustenta, em grande medida, o arranjo curricular da cartografia na formação em Geografia no Brasil, as produções em alfabetização cartográfica e mapeamentos baseados em precisão posicional que é a base para procedimentos de análise espacial, que pode ser resumida como o conjunto de procedimentos em geoprocessamento para exploração, consulta, manipulação e modelagem de dados georreferenciados. Ressalta-se, ainda, que é bastante comum no uso de recursos geotecnológicos, tais como os sistemas de informações geográficas, a ênfase na saída gráfica, por vezes criando equívocos de se considerar um SIG, pela facilitação que oferece para construção de mapas, como um substituto da Cartografia.

Existe, assim, um pressuposto amplamente compartilhado entre os que se dedicam a pesquisas que articulam estes termos - cartografias, representações, análise espacial - que implica no modo de se entender o espacial. Retomaremos estas questões adiante. Neste momento elas nos servem de horizonte e de justificativa para a tomada de um dos termos para desenvolver a argumentação.

O segundo esclarecimento é que para falar de estado da arte optamos pela construção de um quadro de referência com base na institucionalidade da pesquisa e da pós-graduação, em vez de elencar autores e obras. Esta opção foi feita para uma visão mais geral da área e seus arranjos, para entender os territórios que a produção em Cartografia na Geografia conformam, seus agenciamentos, potências, linhas de fuga, para então apresentar algumas pistas para o entendimento das abordagens teóricas e metodológicas. Entendemos que mirar para o lugar da pesquisa em ou com cartografia pode nos dar elementos para falar sobre a produção da pesquisa em cartografia no Brasil e utilizamos dados da CAPES e do CNPq como indicadores do contexto e processo que nos propomos a analisar.

O terceiro esclarecimento é que o foco não será no amplo campo da cartografia contemporânea, mas no que pode ser denominado "Cartografia Geográfica", conjunto de práticas, técnicas, teorias interessadas em fazer com que a cartografia dê língua às geografias produzidas na academia e dialogue com a produção conceitual em Geografia (criando tensionamentos, colaborando no desenvolvimento).

Assim o texto é constituído de uma parte composta de dados como indicadores de processos e suscitadores de reflexões, seguido de uma tentativa de cartografia da Cartografia Geográfica brasileira, por meio do reconhecimento dos territórios e agenciamentos com os quais se compõe, bem como das linhas de fuga ativadoras de processos de desmanchamento e constituição de novos territórios. 


\section{ALGUNS DADOS COMO PONTO DE PARTIDA}

Partimos para a coleta de dados de indicadores de contexto e tendências tendo como questão de fundo para qual (ou quais) geografia (ou geografias) a pesquisa em cartografia desenvolvida no âmbito acadêmico da própria geografia trabalha. Esta questão é ancorada no que pensamos ser crucial no entendimento do estado da arte, que é o fundamento de espaço geográfico a que se refere, que pensamentos sobre ele adensa ou ainda como o constrói.

Formulamos um conjunto de perguntas para guiar nossa busca: Que áreas abrigam na atualidade a pesquisa em cartografia no Brasil? Qual é o lugar da ciência geográfica neste contexto? Qual é a situação atual da pesquisa em cartografia no campo da geografia acadêmica? Quais são suas principais tendências?

As fontes às quais recorremos foram os sítios na internet da CAPES - Coordenação de Aperfeiçoamento de Pessoal de Nível Superior e do CNPq - Conselho Nacional de Desenvolvimento Científico e Tecnológico. Resultados quanti-qualitativos e algumas análises são apresentados a seguir.

\section{Que áreas abrigam na atualidade a pesquisa em cartografia no Brasil?}

Visando construir um panorama geral da área de pesquisa em cartografia no Brasil, consultamos e coletamos informações da base corrente do Diretório dos Grupos de Pesquisa do CNPq (http:// dgp.cnpq.br/buscaoperacional). Este portal permite que sejam acessados os grupos de pesquisa por palavras-chave que podem estar contidas em qualquer campo de entrada de dados: área, nome do grupo, nome da linha de pesquisa e informações textuais.

A palavra-chave que utilizamos foi "cartografia". Optamos por não utilizar termos como "mapa" e "mapeamento", pois são bastante utilizados seja no sentido de "panorama geral", "visão geral", "contexto situacional", seja em abordagens específicas, como "mapa conceitual", para a área de ciências cognitivas e "mapeamento de preferências internas", para pesquisa de mercado na área de engenharia de alimentos, somente para citar alguns exemplos.

Uma busca geral, tomando como referência as grandes áreas e áreas do $\mathrm{CNPq}$, retornou as informações sistematizadas no quadro 1.

Os Grupos de Pesquisa que mencionam cartografia em seu escopo se concentram nas áreas clássicas de aplicação deste conhecimento (Geografia, Geociências, Engenharias, Agronomia). Há, porém uma disseminação em vários outros campos.

As grandes áreas de Ciências Exatas e da Terra, que abriga áreas que produzem mapeamentos específicos, como a Geologia, a Oceanografia, a Geografia Física (especialmente o mapeamento geomorfológico) ou que aplicam geotecnologias ou, ainda, que se dedicam ao estudo dos processos de produção cartográfica básica (como a Geodésia e a Engenharia Cartográfica), e de Ciências Humanas, que abriga a Geografia e a Educação, congregam a maior parte (pouco mais de 70\%) dos Grupos de Pesquisa que lidam com cartografia.

Nas áreas das Ciências Humanas, de Ciências da Saúde e das Ciências Sociais Aplicadas a análise das informações dos Grupos de Pesquisa aponta que em muitos casos a cartografia a que se referem é aquela da proposição filosófica de Gilles Deleuze e Félix Guattari, que conferem ao termo o significado de esquizoanálise, ou seja, análise das linhas de fuga que promovem desmanchamentos de territórios (ROLNIK, 2006). 
Quadro 1: Grupos de Pesquisa CNPq acessados pelo termo “cartografia”, por Área e Grande Área.

\begin{tabular}{|c|c|c|}
\hline Grande Área do CNPQ & Área do CNPQ & $\begin{array}{c}\text { Número de Grupos de } \\
\text { Pesquisa }\end{array}$ \\
\hline \multirow{3}{*}{ Ciências Agrárias } & Agronomia & 10 \\
\hline & Engenharia Agrícola & 2 \\
\hline & Recursos Florestais e Engenharia Florestal & 1 \\
\hline \multirow{3}{*}{ Ciências Biológicas } & Botânica & 1 \\
\hline & Ecologia & 3 \\
\hline & Zoologia & 1 \\
\hline Ciências da Saúde & Saúde Coletiva & 2 \\
\hline \multirow{3}{*}{ Ciências Exatas e da Terra } & Ciência da Computação & 2 \\
\hline & Geociências & 77 \\
\hline & Oceanografia & 4 \\
\hline \multirow{6}{*}{ Ciências Humanas } & Antropologia & 3 \\
\hline & Educação & 11 \\
\hline & Geografia & 47 \\
\hline & História & 6 \\
\hline & Psicologia & 2 \\
\hline & Sociologia & 6 \\
\hline \multirow{6}{*}{ Ciências Sociais Aplicadas } & Administração & 1 \\
\hline & Arquitetura e Urbanismo & 3 \\
\hline & Comunicação & 1 \\
\hline & Direito & 1 \\
\hline & Planejamento Urbano e Regional & 4 \\
\hline & $\begin{array}{l}\text { Turismo } \\
\text { Engenharia Civil }\end{array}$ & $\frac{1}{10}$ \\
\hline \multirow{6}{*}{ Engenharias } & Engenharia de Materiais e Metalúrgica & 1 \\
\hline & Engenharia de Minas & 1 \\
\hline & Engenharia de Transportes & 3 \\
\hline & Engenharia Elétrica & 1 \\
\hline & Engenharia Mecânica & 1 \\
\hline & Engenharia Sanitária & 2 \\
\hline \multirow{3}{*}{ Linguística, Letras e Artes } & Artes & 1 \\
\hline & Letras & 1 \\
\hline & Lingüística & 8 \\
\hline TOTAL & & 218 \\
\hline
\end{tabular}

Fonte: Diretório dos Grupos de Pesquisa do CNPq. http://dgp.cnpq.br/buscaoperacional. Acesso em abril de 2011. Dados coletados e organizados por Girardi, 2011.

Qual é o lugar da ciência geográfica no contexto dos Grupos de Pesquisa em cartografia no Brasil?

Como indicador para esta questão, focamos a coleta e a análise nas áreas "Geografia" e "Educação" na grande área Ciências Humanas e na área "Geociências" na grande área "Ciências Exatas e da Terra", pois são estes os campos de vinculação mais usuais das pesquisas em Geografia no Brasil. Nas áreas de Geociências e de Educação, por abrigarem uma ampla diversidade de áreas de conhecimento, foi necessário refinar a busca para os Grupos de Pesquisa de Geografia Física e Educação Geográfica, respectivamente, o que foi feito a partir da consulta às informações dos próprios grupos. Os Grupos de Pesquisa que lidam com cartografia na Geografia correspondem a 36\% do total de Grupos de Pesquisa que lidam com cartografia, consideradas todas as áreas de conhecimento. Os resultados da coleta e organização de dados estão expressos no quadro 2. 
Quadro 2: Grupos de Pesquisa CNPq que lidam com a cartografia na Geografia.

\begin{tabular}{|l|c|l|c|c|c|}
\hline \multicolumn{1}{|c|}{ Grande Área } & $\begin{array}{c}\text { Total da } \\
\text { grande } \\
\text { área }\end{array}$ & Área & $\begin{array}{c}\text { Nómero de } \\
\text { Grupos de } \\
\text { área } \\
\text { Pesquisa da } \\
\text { sub-área }\end{array}$ & $\begin{array}{c}\text { Sub-área } \\
27\end{array}$ \\
\hline Ciências Exatas e da Terra & 83 & Geociências & 77 & Geografia Física & Educação Geográfica \\
\hline \multirow{2}{*}{ Ciências Humanas } & 75 & Educação & 11 & Geografia \\
\cline { 2 - 6 } & & Geografia & 47 & 47 \\
\hline
\end{tabular}

Fonte: Diretório dos Grupos de Pesquisa do CNPq. http://dgp.cnpq.br/buscaoperacional. Acesso em abril de 2011. Dados coletados e organizados por Girardi, 2011.

\section{Qual é a situação atual da pesquisa em cartografia no campo da geografia acadêmica?}

Objetivando dar visibilidade à situação atual da pesquisa em cartografia no âmbito da pesquisa geográfica foram realizados levantamentos no Diretório dos Grupos de Pesquisa do CNPq (http://dgp. cnpq.br/buscaoperacional) e no Banco de Teses da CAPES (http://capesdw.capes.gov.br/capesdw). Foi analisada a dimensão dos grupos e teses em cartografia em relação ao universo da Geografia .

Em relação ao universo dos Grupos de Pesquisa em Geografia, na data da coleta dos dados existiam 254 grupos, sendo 189 vinculado à área "Geografia", 32 vinculados à área "Educação" e 33 vinculados à área "Geociências". A quadro 3 expressa os valores absolutos e relativos do universo dos Grupos de Pesquisa que lidam com cartografia no universo dos Grupos de Pesquisa da Geografia.

Quadro 3: Grupos de Pesquisa CNPq que lidam com a cartografia na Geografia em relação ao universo dos Grupos de Pesquisa em Geografia.

\begin{tabular}{|l|c|c|c|}
\hline \multicolumn{1}{|c|}{ Área } & $\begin{array}{c}\text { Grupos de Pesquisa em } \\
\text { Geografia }\end{array}$ & $\begin{array}{c}\text { Número de Grupos de Pesquisa } \\
\text { em Geografia que lidam com } \\
\text { Cartografia }\end{array}$ & $\begin{array}{c}\text { \% de Grupos de Pesquisa } \\
\text { em Geografia que lidam com } \\
\text { Cartografia }\end{array}$ \\
\hline Educação & 32 & 5 & 16 \\
\hline Geociências & 33 & 27 & 82 \\
\hline Geografia & 189 & 47 & 25 \\
\hline TOTAL & $\mathbf{2 5 4}$ & $\mathbf{7 9}$ & $\mathbf{3 1}$ \\
\hline
\end{tabular}

Fonte: Diretório dos Grupos de Pesquisa do CNPq. http://dgp.cnpq.br/buscaoperacional. Acesso em abril de 2011. Dados coletados e organizados por Girardi, 2011.

Tais dados, evidentemente, tem de ser tomados com cautela, como indícios e não como definitivos em relação às áreas. É histórica a luta da área de Geografia para ajustes junto às estruturas do CNPq e é incorreto, por exemplo, afirmar que hoje os grupos de pesquisa cuja ênfase é Geografia Física concentram-se na área de Geociências. Contudo, a informação de que cerca de um terço dos Grupos de Pesquisa em Geografia articula a cartografia em seus fazeres é bastante confiável.

No que se refere às teses, foram levantadas informações junto à CAPES (dados das avaliações trienais dos programas de pós-graduação em Geografia 2004-2006 e 2007-2009) quanto às instituições que possuem programas de pós-graduação em nível de doutoramento em Geografia e a quantidade das teses defendidas. Estes dados foram comparados com o levantamento realizado no banco de teses da CAPES, no qual foram identificadas 36 teses com cartografia em Geografia defendidas no período 2004-2009. Os dados são apresentados na quadro 4. 
Quadro 4: Instituições que possuem Programa de Doutorado em Geografia e que tiveram teses defendidas em cartografia, número total de teses defendidas e número de trabalhos que lidam com a cartografia na Geografia (CG), no período 2004-2009.

\begin{tabular}{|l|l|c|c|c|}
\hline \multicolumn{1}{|c|}{ Sigla } & \multicolumn{1}{|c|}{ Instituição } & $\begin{array}{c}\text { No. Total } \\
\text { de Teses }\end{array}$ & $\begin{array}{c}\text { No. De } \\
\text { Teses em } \\
\text { CG }\end{array}$ & $\begin{array}{c}\text { \% Teses } \\
\text { em CG }\end{array}$ \\
\hline PUC MG & Pontifícia Universidade Católica - MG & 19 & 2 & 10,5 \\
\hline UFMG & Universidade Federal de Minas Gerais & 20 & 3 & 15,0 \\
\hline UFPE & Universidade Federal de Pernambuco & 7 & 1 & 14,3 \\
\hline UFRJ & Universidade Federal do Rio de Janeiro & 118 & 6 & 5,1 \\
\hline UFS & Universidade Federal de Sergipe & 32 & 2 & 6,3 \\
\hline UFU & Universidade Federal de Uberlândia & 31 & 2 & 6,5 \\
\hline UNESPPP & Universidade Estadual Paulista-Presidente Prudente & 85 & 4 & 4,7 \\
\hline UNESP RC & Universidade Estadual Paulista - Rio Claro & 77 & 5 & 6,5 \\
\hline USP GF & Universidade de São Paulo-Geografia Física & 116 & 1 & 15,2 \\
\hline USP GH & Universidade de São Paulo-Geografia Humana & $\mathbf{5 7 1}$ & $\mathbf{3 6}$ & 0,9 \\
\hline TOTAL & & & $\mathbf{6 , 3}$ \\
\hline
\end{tabular}

Fonte: Banco de Teses da CAPES (http://capesdw.capes.gov.br/capesdw) e Relatórios de Avaliação dos Programas de Pós-Graduação em Geografia (http://.capes.gov.br/avaliação/resultados-da-avaliacao-de-programas). Acesso em abril de 2011. Dados coletados e organizados por Girardi, 2011.

O efetivo de teses defendidas em ou com Cartografia responde a 6,3\% do total de teses defendidas em Geografia, considerando somente aquelas instituições em que houve a ocorrência de trabalhos com esta temática. Buscamos classificar estas teses pelas linhas de pesquisa, mas este esforço não revelou bons resultados, uma vez que houve uma significativa reformulação das linhas de pesquisa nas instituições, fruto em grande parte de solicitações de adequação por parte da CAPES nos anos recentes. Além disso, a palavra "cartografia" não aparece dentre as nominações de linhas de pesquisa dos programas de pós-graduação em Geografia no Brasil atualmente.

Tentando identificar o campo de conhecimento na qual as teses em ou com Cartografia foram realizadas, substituímos a informação sobre a linha de pesquisa pela área de atuação do orientador da tese, a partir da consulta a seus currículos na Plataforma Lattes do CNPq, e os resultados estão expressos na quadro 5.

Quadro 5: Principais áreas de atuação de orientadores de teses em cartografia nos Programas de Pós-Graduação em Geografia (1987-2009)

\begin{tabular}{|l|c|}
\hline \multicolumn{1}{|c|}{ Área principal de atuação do orientador } & \multicolumn{1}{|c|}{ Ocorrências } \\
\hline Cartografia Escolar & 13 \\
\hline Geotecnologias & 12 \\
\hline Cartografia Temática e Sistemática & 9 \\
\hline Climatologia & 6 \\
\hline Geografia Física & 5 \\
\hline Geomorfologia & 5 \\
\hline Análise e Planejamento Urbano e Regional & 4 \\
\hline Geografia urbana & 3 \\
\hline Epistemologia da geografia & 2 \\
\hline Geografia Econômica & \\
\hline Geografia Agrária & \\
\hline Educação & \\
\hline Análise e Gestão Ambiental & 1 \\
\hline TOTAL & 1 \\
\hline
\end{tabular}

Fonte: Banco de Teses da CAPES (http://capesdw.capes.gov.br/capesdw). Acesso em abril de 2011. Dados coletados e organizados por Girardi, 2011. 
Tanto se observa um esperado adensamento do número de teses orientadas por docentes engajados nas áreas de Cartografia Temática e Sistemática, Cartografia Escolar e Geotecnologias, como é relevante o fato de que cerca de $50 \%$ das teses em cartografia são orientadas por docentes de variadas áreas do conhecimento geográfico.

Quais são as principais tendências da pesquisa em cartografia no âmbito da pesquisa geográfica?

Como indicadores dos campos e tendências atuais da pesquisa em Cartografia no âmbito da pesquisa geográfica foram compiladas e analisadas as informações constantes nos registros dos 79 Grupos de Pesquisa quanto às repercussões, objetivos e linhas de pesquisa e das 64 teses por meio de seus resumos disponíveis no Banco de Teses da CAPES.

Para a classificação dos Grupos de Pesquisa e das teses foi elaborada uma lista preliminar por ocorrência, posteriormente refinada nos ramos abaixo descritos quanto à ênfase dada à Cartografia em cada um deles.

Abordagens teóricas e metodológicas: Ênfase na discussão das implicações da cartografia no âmbito teórico metodológico da Geografia.

Aplicações geotecnológicas: Ênfase na utilização de sistemas de informações geográficas, técnicas de geoprocessamento, sensoriamento remoto para a abordagem de temas, em especial voltados ao planejamento, análise e gestão territorial, ambiental e urbana.

Cartografia Escolar: Ênfase no desenvolvimento de aplicações da cartografia em situações escolares, nos diferentes níveis de ensino.

Cartografia histórica: Ênfase na análise de mapas construídos em períodos históricos diversos, utilizando-os, de modo geral, como fontes historiográficas para abordagem de configurações territoriais atuais.

Cartografia Tátil: Ênfase no desenvolvimento de recursos para construção e leitura de mapas por pessoas cegas e de baixa visão. Normalmente aborda público ou situações escolares.

Linguagem de mapas temáticos/semiologia gráfica: Ênfase nos estudos da linguagem gráfica para elaboração de mapas, particularmente utilizando a Semiologia Gráfica de Jacques Bertin como aporte.

Mapeamento geomorfológico: Ênfase na produção de mapeamentos geomorfológicos em escalas diversas a partir de levantamentos e análises de feições do relevo.

Visualização cartográfica: Ênfase no estudo de procedimentos voltados para a construção e utilização de produtos cartográficos virtuais ou digitais interativos.

As ênfases foram sistematizadas nos blocos temáticos "Aplicação Geotecnológica" (AG), "Aplicação em Ensino de Geografia" (AE) e "Abordagens Teórico-Metodológicas" (AT), conforme apresentado no quadro 1.

No quadro 6 são apresentadas as quantidades de teses e Grupos de Pesquisa a partir da sua classificação nos blocos temáticos estabelecidos.

Quadro 6: Blocos temáticos de pesquisa em cartografia na Geografia

\begin{tabular}{|l|l|}
\hline \multicolumn{1}{|c|}{ Bloco Temático } & Enfase dada aos grupos para Cartografia \\
\hline \multirow{2}{*}{ Aplicação Geotecnológica (AG) } & Aplicações geotecnológicas \\
\cline { 2 - 2 } & Mapeamento geomorfológico \\
\hline \multirow{2}{*}{ Aplicação em Ensino de Geografia (AE) } & Cartografia escolar \\
\cline { 2 - 2 } & Cartografia Tátil \\
\hline \multirow{2}{*}{ Abordagens Teórico Metodológicas (AT) } & Linguagem de mapas temáticos/ semiologia gráfica \\
\cline { 2 - 2 } & Cartografia histórica \\
\cline { 2 - 2 } & Abordagens teóricas e metodológicas \\
\cline { 2 - 2 } & Visualização cartográfica \\
\hline
\end{tabular}

Fontes: Diretório dos Grupos de Pesquisa do CNPq. http://dgp.cnpq.br/buscaoperacional e Banco de Teses da CAPES (http://capesdw.capes.gov.br/capesdw). Acesso em abril de 2011. Dados coletados e organizados por Girardi, 2011. 
Quadro 7: Grupos de Pesquisa e Teses por Blocos Temáticos de pesquisa em cartografia na Geografia

\begin{tabular}{|l|c|c|}
\hline \multicolumn{1}{|c|}{ Bloco Temático } & $\begin{array}{c}\text { Grupos de Pesquisa } \\
\mathbf{( 2 0 1 1 )}\end{array}$ & $\begin{array}{c}\text { Teses defendidas } \\
(\mathbf{1 9 9 8 - 2 0 0 9 )}\end{array}$ \\
\hline Aplicação Geotecnológica (AG) & 42 & 28 \\
\hline Aplicação em Ensino de Geografia (AE) & 19 & 15 \\
\hline Abordagens Teórico-Metodológicas (AT) & 18 & 21 \\
\hline TOTAL & 79 & 64 \\
\hline
\end{tabular}

Fontes: Diretório dos Grupos de Pesquisa do CNPq. http://dgp.cnpq.br/buscaoperacional e Banco de Teses da CAPES (http://capesdw.capes.gov.br/capesdw). Acesso em abril de 2011. Dados coletados e organizados por Girardi, 2011.

Completando os indicadores da situação da pesquisa em ou com Cartografia na Geografia, é apresentada na quadro 7 a distribuição das teses defendidas pelas áreas de atuação dos orientadores e pelos blocos temáticos sistematizados e no gráfico 1 é apresentada a ocorrência, no tempo, destas teses, considerando os blocos temáticos.

Quadro 8: Distribuição das teses pelas áreas principais de atuação dos orientadores e blocos temáticos

\begin{tabular}{|c|c|c|c|c|}
\hline \multirow{2}{*}{ Área principal de atuação do orientador } & \multirow{2}{*}{ Ocorrências } & \multicolumn{3}{|c|}{ Ênfase das orientações } \\
\hline & & AG & $\mathbf{A E}$ & AT \\
\hline Cartografia Escolar & 13 & & 8 & 5 \\
\hline Geotecnologias & 12 & 9 & 1 & 2 \\
\hline Cartografia Temática e Sistemática & 9 & 4 & 1 & 4 \\
\hline Climatologia & 6 & 2 & 1 & 3 \\
\hline Geografia Física & 5 & 4 & & 1 \\
\hline Geomorfologia & 5 & 4 & & 1 \\
\hline Análise e Planejamento Urbano e Regional & 4 & 4 & & \\
\hline Geografia urbana & 3 & 1 & & 2 \\
\hline Epistemologia da geografia & 2 & & 1 & 1 \\
\hline Geografia Econômica & 2 & & 1 & 1 \\
\hline Geografia Agrária & 1 & & & 1 \\
\hline Educação & 1 & & 1 & \\
\hline Análise e Gestão Ambiental & 1 & & 1 & \\
\hline TOTAL & 64 & 28 & 15 & 21 \\
\hline
\end{tabular}

Fonte: Banco de Teses da CAPES (http://capesdw.capes.gov.br/capesdw). Acesso em abril de 2011. Dados coletados e organizados por Girardi, 2011.

Apontamos anteriormente que cerca de 50\% das teses em cartografia na Geografia foram orientadas por docentes de áreas variadas do conhecimento geográfico que não das Cartografias e Geotecnologias. Os dados da tabela 7 chamam a atenção para o fato de que docentes destas outras áreas orientaram cerca de $50 \%$ das teses do bloco temático "Abordagens teórico-metodológicas". 
Gráfico 1: Distribuição das teses pelas áreas pelos blocos temáticos e pelo ano de defesa

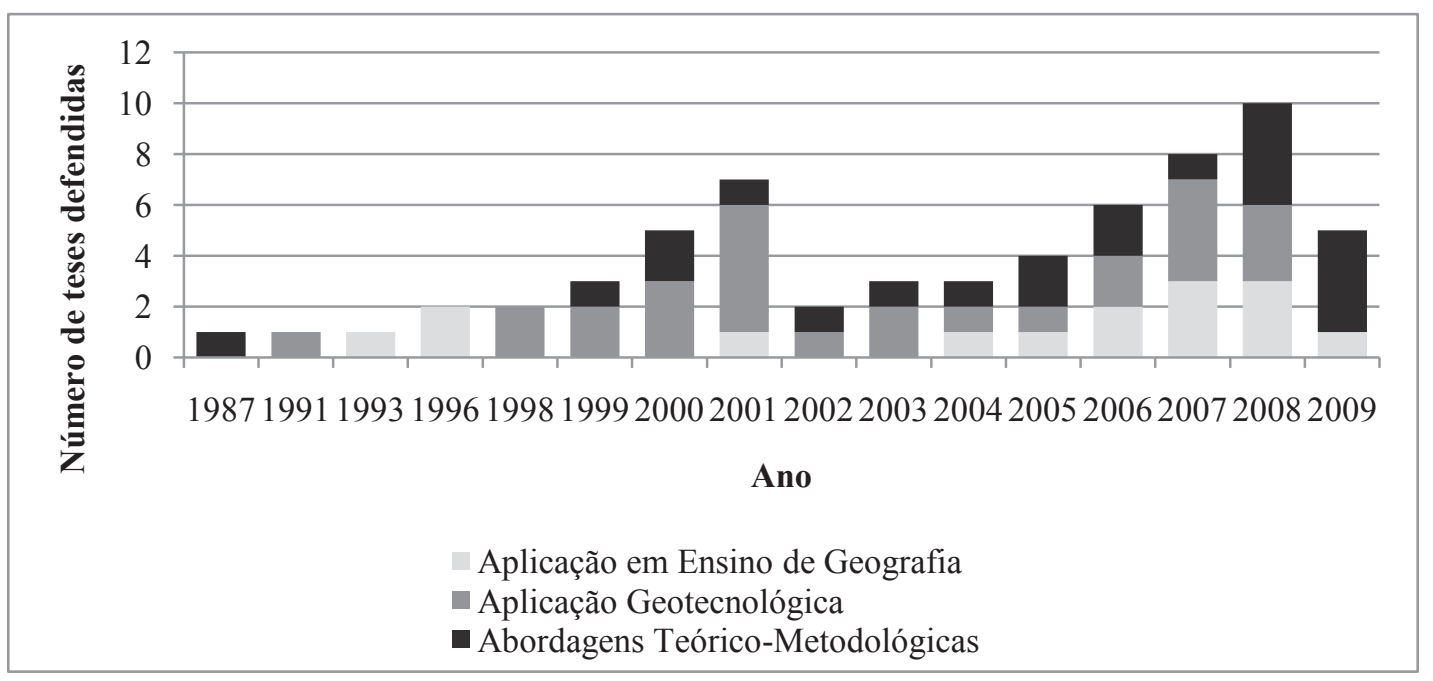

Fonte: Banco de Teses da CAPES (http://capesdw.capes.gov.br/capesdw). Acesso em abril de 2011. Dados coletados e organizados por Girardi, 2011.

Já o gráfico revela que a pesquisa em cartografia na Geografia nas últimas décadas do século XX era efêmera e apresentou uma tendência de regularidade e aumento na virada do século, sustentada pela pesquisa em aplicações geotecnológicas. Mostra, também, e que nos últimos anos houve um significativo aumento do número de teses, marcadamente em abordagens teórico-metodológicas e em aplicações em ensino de Geografia.

\section{APONTAMENTOS PARA UMA CARTOGRAFIA DA CARTOGRAFIA GEOGRÁFICA BRASILEIRA}

A tentativa que fazemos aqui, a título de estado da arte, é de articular elementos para uma cartografia da Cartografia Geográfica brasileira. Os dados que levantamos como indicadores de processos permitem elencar questões para reflexão. Cabe reafirmar que optamos por indicadores institucionais de pesquisa (Grupos de Pesquisa) e pós-graduação (Teses de Doutoramento) por entendê-las como geradoras dinâmicas de produções e assim fornecem elementos para o entendimento do campo.

Convém esclarecer que quando falamos em cartografia da Cartografia Geográfica Brasileira tomamos a cartografia, letra minúscula, como método analítico com inspiração na filosofia de Gilles Deleuze e Félix Guattari, donde tomaremos algumas idéias para refletir sobre um campo, que é a Cartografia (letra maiúscula) Geográfica Brasileira. A cartografia nesta perspectiva filosófica implica em um acompanhamento do desmanchamento e formação de territórios. O desmanchamento acontece quando territórios anteriores perdem sentido, por não haver neles mais a passagem de afetos. Afeto não se refere somente à dimensão psíquica individual (mas também a ela), mas à força que faz o mundo se movimentar, ou seja, tudo aquilo que ativa, que afeta.

Uma tal cartografia implica, assim, em entender os territórios (campos de estabilidade relativa), as linhas de fuga, ou processos de desmanchamento dos territórios (a desterritorialização) e a formação dos novos territórios (a reterritorialização) e os agenciamentos que acompanham toda esta dinâmica, que é feita o tempo todo, em vários níveis. Não temos a pretensão de dar conta de todos estes níveis, mas de apontar elementos que julgamos relevantes para a constituição de um panorama geral.

Podemos dizer que o território estável, com contornos definidos que foi a Cartografia para a Geografia no passado está em processo de desmanchamento. Os rompimentos dos limites deste 
território foram sendo promovidos por vários fatores. Em escritos anteriores (GIRARDI, 2003; 2004) fizemos uma revisão sobre o contexto do desmanchamento deste território relativamente estável a partir dos anos 1970, momento no qual concorriam os desdobramentos institucionais do movimento de renovação da Geografia, a introdução das geotecnologias em vários âmbitos da vida social e as implicações disto no mercado e as mudanças nas políticas educacionais, inicialmente com a universalização do ensino básico (Lei 5.692/71) e posteriormente com a Lei de Diretrizes e Bases da Educação (Lei 9.394/96).

Fonseca $(2004 ; 2007)$ adensou e aprofundou as questões epistemológicas emergentes deste contexto, que podemos sintetizar na diferença entre modos de compreensão da espacialidade, entre o fundamento cartográfico no espaço cartesiano (espaço absoluto, espaço como superfície terrestre) e a flexibilidade do espaço geográfico (espaço relativo).

Na virada do Século XX para o Século XXI nós, pesquisadores da Cartografia na Geografia, habitávamos este território em desmanchamento pelos fatores institucionais, políticos, ideológicos e epistemológicos mencionados. Obviamente que esta desterritorialização só faz sentido se mirada no interior das estruturas de ensino e pesquisa da própria Geografia. Fora dela, como dizem Crampton e Krigyer (2006) a Cartografia é um riquíssimo campo indisciplinado e ao mesmo tempo transdisciplinar.

O indisciplinamento a que os autores se referem ancora-se na emergência de práticas imaginativas de mapeamento, ou seja, usos sociais do mapa em várias esferas da vida, e na crítica à política do mapeamento, como por exemplo, os mecanismos de controle das informações e os paradigmas a partir dos quais os mapas são construídos. A transdisciplinaridade desdobra-se basicamente do processo disseminação de práticas cartográficas em várias áreas do conhecimento científico pela facilitação de acesso a dados e a aplicativos computacionais e traduz-se no desenvolvimento de "capacidades de mapeamento cada vez mais onipresentes e móveis” Crampton e Krigyer (2006, p.15). Os universos de pesquisa e pós-graduação que analisamos são significativos neste sentido: dos 218 Grupos de Pesquisa que atuam em Cartografia, 79 estão no campo da Cartografia Geográfica; das 150 teses que trabalham com Cartografia, 64 estão nos programas de pós-graduação da Geografia.

Duas vias de revalorização (duas reterritorializações principais) da Cartografia na Geografia eram apontadas na virada do século: o ensino de geografia, desdobrado na Cartografia Escolar e a aplicação das geotecnologias (na pesquisa, no ensino e nas atividades técnicas do "mercado de trabalho"). Tanto os Grupos de Pesquisa como as teses de doutoramento apontam estas reterritorializações, estes novos territórios, que neste texto denominamos de Aplicação Geotecnológica (AG), Aplicação em Ensino de Geografia (AE) e Abordagens Teórico-Metodológicas (AT). Para o entendimento destes novos territórios e apontamentos de seus novos processos de desterritorialização em curso, abordemos os agenciamentos que conformaram e conformam cada um.

O território "Aplicação Geotecnológica"

Há uma colagem muito evidente das produções neste território com os termos (e práticas) de planejamento, análise e gestão territorial, regional, ambiental, da saúde. Desdobram-se em proposições para zoneamento (ambiental, ecológico-econômico, urbano e outros), mapeamento de unidades (de paisagem, geomorfológicas), modelagem, cenarização. Há um engajamento regular dos grupos de pesquisa deste território com setores da administração pública e do mercado, sob formas de transferência tecnológica, consultorias e atividades afins, sob a justificativa geral da instrumentalização para tomada de decisões.

Subjaz às Cartografias produzidas neste território uma noção do espacial como "superfície de uma completa horizontalidade", "simultaneidade completa na qual todas as interconexões já tenham sido estabelecidas" (Massey, 2008, p. 160-161). A maior parte das aplicações geotecnológicas opera com a mesma métrica, a da geometria euclidiana, que dá língua para esta noção de espacialidade estável e já posta, disponível para a descoberta. O paradigma representacional é, portanto, hegemônico neste território. 
Os conceitos e categorias geográficas de escala, território, região e paisagem são recorrentemente abordados nas produções deste território, em grande medida para fundamentar ou justificar a própria aplicação geotecnológica. É neste âmbito que encontramos a análise espacial cuja finalidade é, segundo Câmara et al. (2004, p. 14), "a escolha de um modelo inferencial [variação contínua, variação discreta ou processos pontuais, ou a combinação destes] que considere explicitamente o relacionamento espacial presente no fenômeno". Por espacial, neste caso, considera-se o que é georreferenciável, localizável num sistema de coordenadas.

São poucos os Grupos de Pesquisa e teses que abordam em profundidade a estrutura de sistemas de informação; o predomínio neste território é a aplicação mesma, nas atividades descritas anteriormente. Compõem também o agenciamento deste território as disciplinas de graduação e pós-graduação nos cursos de Geografia, amplamente voltadas para a habilitação para a utilização de ferramentas computacionais para aplicações específicas, e a emergência de eventos específicos para a discussão da temática, como o CARTOGEO - Simpósio Internacional Caminhos Atuais da Cartografia na Geografia, que teve sua primeira edição em 2006 e a segunda em 2010.

Linhas de fuga deste território podem ser identificadas pelas atividades de mapeamento participativo (negociação do tipo de base, de fonte, de informação e de saída gráfica com os atores envolvidos no espaço considerado) e colaborativo (compartilhamento da produção cartográfica em plataformas virtuais de fontes abertas), bem como pela pesquisa em fundos de mapa com métricas outras que não a geometria euclidiana (como é o caso da produção de anamorfoses). Estas nos parecem ser as vias políticas de desestabilização deste território, contudo ainda bem pontuais.

\section{O território "Aplicação em Ensino de Geografia"}

A conformação deste território está amplamente vinculada às mudanças na política educacional brasileira promovida pela Lei de Diretrizes e Bases da Educação, particularmente em seus desdobramentos nos Parâmetros Curriculares Nacionais para o ensino básico. O pré-território caracterizava-se por desenvolvimentos pontuais na pesquisa do uso de mapas no ensino de Geografia (com destaque para as professoras Lívia de Oliveira e Maria Elena Simielli) e por uma sub ou não utilização de mapas em situações de escolarização formal, desdobradas em grande medida de deficiências formativas e de mudanças paradigmáticas no âmbito do ensino decorrentes do movimento de renovação da Geografia. Os Parâmetros Curriculares Nacionais colocam a linguagem cartográfica no centro da discussão pedagógica, amplamente amparada nas teorias da construção da noção de espaço na criança, de Jean Piaget.

A necessidade de capacitação de professores do ensino básico em atendimento às demandas dos PCNs, a produção de material cartográfico para o ensino de Geografia (como os materiais de apoio didático em Cartografia, os atlas escolares e os atlas municipais) contribuíram com a valorização da área como campo de pesquisa geográfica. Incluem-se nesta modalidade a produção cartográfica em cartografia tátil. $\mathrm{Na}$ atualidade existem 19 grupos de pesquisa que articulam a Cartografia no ensino de Geografia, em vários níveis, em suas linhas de pesquisa.

A dinamização da área é também revelada pela crescente produção acadêmica, em número de teses defendidas nos últimos anos. É também revelador que orientadores de doutorado com engajamento área de Cartografia Escolar articulam um efetivo significativo de pesquisas na área de Cartografia na Geografia. A inclusão de disciplina de Cartografia Escolar nos currículos de licenciatura em Geografia começa a ser proposta (ainda que com pouca efetivação até o momento). Compõe o quadro dos agenciamentos que conformam este território a visibilidade internacional que pesquisadores da Cartografia para crianças e escolares, especificamente no âmbito da comissão de cartografia e crianças da Associação Cartográfica Internacional, que deu impulso à criação do Colóquio de Cartografia para Crianças e Escolares, em 1995 (que terá neste ano sua sétima edição) e a absorção institucional da área na Sociedade Brasileira de Cartografia, especificamente na promoção do Prêmio Lívia de Oliveira de Cartografia para Crianças. 
O crescimento institucional e acadêmico deste território é um fator de sua estabilização e ao mesmo tempo um campo de promoção de sua própria desterritorialização e é precisamente isto que compõe sua dinâmica. No campo teórico, muito da produção deste território consiste ainda numa adaptação, para do ensino, do campo maior da Cartografia na Geografia, portanto constituída sobre as mesmas bases. O paradigma representacional é ainda majoritário no campo, o que pode ser observado na maneira como se constroem metodologicamente as estratégias de elaboração e uso de mapas em situação escolar. A passagem da última etapa de construção da noção de espaço na criança como condição para adentrar no universo da linguagem cartográfica, que são as relações euclidianas, trabalha para estabilizar a geometria euclidiana do mapa como natureza das imagens cartográficas. Somado a isto, as escalas que são valorizadas nas diferentes séries (ou anos) do ensino (local, estadual, regional, nacional, mundial) são acompanhadas de mapas que, antes de tudo, afirmam o político-administrativo como recorte privilegiado da Geografia, conforme foi apontado por Oliveira Jr. (2009).

Linhas de fuga deste território tem sido constituídas nas interfaces das pesquisas com outras áreas do conhecimento escolar, haja vista a potência interdisciplinar das pesquisas em educação, e com proposições ligadas à centralidade da cultura, que se desdobram no entendimento da Cartografia como uma das linguagens geográficas, compartilhando com outras linguagens potências e problemáticas. O livro recentemente publicado, Novos rumos da cartografia escolar, organizado por Almeida (2011), é revelador neste sentido e aponta para novas possíveis reterritorializações.

\section{O território "Abordagens Teórico-Metodológicas"}

248 Este é, com efeito, um território híbrido. Não caracteriza, como os outros, um campo temático claramente identificado. Entrecruza, o tempo todo, os outros dois territórios, mas particulariza-se por um "olhar para dentro", por mergulhar na investigação das relações da Geografia com a Cartografia. Os elementos centrais de reconhecimento deste território são as miradas para a Cartografia Geográfica, tendo ênfase na Comunicação Cartográfica, incluindo a Semiologia Gráfica, na Cartografia na Geografia Contemporânea (aspectos epistemológicos), na Modelização (com uso de recursos tecnológicos ou não), na Cartografia como Linguagem Geográfica, na Visualização Cartográfica.

Não há, neste território, um paradigma claro. Sua característica é justamente a de abrigar produções pautadas em diferentes paradigmas científicos e espaciais. É revelador que um número significativo das teses enquadradas neste âmbito tiveram como orientadores docentes de variadas áreas do conhecimento, da Geografia Agrária à Climatologia, da Geografia Econômica à Geomorfologia. As justificativas para isto são tanto a inexistência, no momento da proposição do projeto de tese, de linha de pesquisa ou orientador da área de Cartografia, como a dificuldade de desenvolvimento de investigações críticas em estruturas hegemônicas de pensamento e práticas cartográficas.

Desdobra disto uma diversidade de amparos, em campos como o da Geografia Cultural, das Ciências Cognitivas, da Psicologia Social, da Filosofia, da Epistemologia Geográfica, das Ciências da Informação, da Educação, da História, da Computação Gráfica, da Arte e tantos outros.

Este território está, assim, sempre se desterritorializando. Tem potência para ser uma força desestabilizadora dos outros territórios, bem como abertura para reterritorializar-se nos outros, compor com eles novos territórios.

\section{CONSIDERAÇÕES FINAIS}

Kitchin, Perkins e Dodge (2009) apresentam dois principais campos de fundamentos ontológicos e epistemológicos da cartografia: a representacional (o mapa é uma tradução gráfica de um mundo existente) e a pós-representacional (o mapa cria mundos tanto quanto o mundo cria mapas). Isto implica em noções distintas de espacialidade. 
Ao analisarmos a conformação dos territórios da Cartografia na Geografia ("Aplicação Geotecnológica", "Aplicação em Ensino de Geografia" e "Abordagens Teórico-Metodológicas”) verificamos que nos territórios de "aplicação" há a predominância da valorização da localização de fenômenos na superfície terrestre. Assim, os fenômenos, mesmo os sociais, compõem a "natureza" daquele ponto ou recorte e isto permite que sejam "representados" nos moldes clássicos da Cartografia pautada na geometria euclidiana, por que lhes impomos sincronias. O paradigma representacional sustenta, assim, o discurso e a prática hegemônica da Cartografia na Geografia na atualidade. Esta, portanto, é a que se apresenta como Cartografia maior.

O conceito de maior em Deleuze e Guattari não tem o sentido de mais importante, ou numérica ou dimensionalmente superior, mas sim de estabilização, de hegemonização, de constância, de metro padrão que serve para medir-se a si mesmo (Deleuze e Guattari, 1995). O menor é o que promove a variação e faz desestabilizar e expandir o maior e, assim, o devir é sempre característica da minoridade.

A Cartografia menor é então este movimento da crítica, da criação, da incorporação do maior para fazê-lo dizer outra coisa, de desestabilização do representacional. Não se quer dizer, com isso, que se propõe uma ancoragem forçada da Cartografia e dos mapas na Geografia. Se se faz Geografia sem mapas (como vimos, a pesquisa em e com Cartografia corresponde a 6,3\% do total de teses defendidas nas instituições que abrigam este conhecimento como campo de pesquisa) é porque os mapas já não dão língua às Geografias.

A título de conclusão de um estado da arte nesta área, entendo que a Cartografia Geográfica, e as linguagens que articula, oferece sua contribuição à ciência geográfica justamente pela sua potência de minoridade e nos territórios identificados observam-se os movimentos deste processo.

\section{REFERÊNCIAS BIBLIOGRÁFICAS}

ALMEIDA, Rosângela Doin (org). Novos rumos da cartografia escolar: currículo, linguagem e tecnologia. São Paulo: Ed. Contexto, 2011. 192p.

CÂMARA, G.; MONTEIRO, A.V.M.; DRUCK, S.; CARVALHO, M.S. Análise Espacial e Geoprocessamento. In. (eds) Análise Espacial de Dados Geográficos. Brasília: EMBRAPA, 2004. Cap. 1, p. 1-26. Disponível em <http://www.dpi.inpe.br/gilberto/livro/analise/cap1-intro.pdf $>$. Acesso em: abr. 2011.

CAPES. Coordenação de Aperfeiçoamento de Pessoal de Nível Superior. Banco de Teses. Disponível em $<$ http://capesdw.capes.gov.br/capesdw>. Acesso em: abr. 2011.

CNPq. Conselho Nacional de Desenvolvimento Científico e Tecnológico. Diretório dos Grupos de Pesquisa - Base corrente. Disponível em <http://dgp.cnpq.br/buscaoperacional>. Acesso em: abr. 2011.

CNPq. Conselho Nacional de Desenvolvimento Científico e Tecnológico. Plataforma Lattes. Disponível em $<$ http://buscatextual.cnpq.br/buscatextual/busca.do>. Acesso em: abr. 2011

CRAMPTON, Jeremy W.; KRYGIER, John. An Introduction to Critical Cartography. ACME: An International E-Journal for Critical Geographies, v.4, n.1, p.11-33, 2006.

DELEUZE, Gilles; GUATTARI, Félix. Mil Platôs: capitalismo e esquizofrenia, vol. 2. São Paulo: Ed. 34 , 1995. 112p.

DELEUZE, Gilles; GUATTARI, Félix. Mil Platôs: capitalismo e esquizofrenia, vol. 5. São Paulo: Ed. 34, 1997. 240p.

FONSECA, Fernanda Padovesi da. A inflexibilidade do espaço cartográfico, uma questão para a Geografia: análise das discussões sobre o papel da Cartografia. 2004. 250 f. Tese (Doutorado em Geografia Física)-Universidade de São Paulo, São Paulo, 2004.

FONSECA, Fernanda Padovesi da. O potencial analógico dos mapas. Boletim Paulista de Geografia, São Paulo, n. 87, p. 85-110, dez. 2007.

GIRARDI, Gisele. A cartografia na geografia brasileira a partir dos anos 1970: notas para a compreensão de uma situação ainda a ser superada. In: CONGRESSO BRASILEIRO DE GEÓGRAFOS, 6.; 2004, 
Goiânia. Anais... Goiânia: AGB, 2004. CD-ROM

GIRARDI, Gisele. Cartografia geográfica: considerações críticas e proposta para ressignificação de práticas cartográficas na formação do profissional em geografia. 2003. 193 f. Tese (Doutorado em Geografia Física)-Universidade de São Paulo, São Paulo, 2003.

KITCHIN, Rob; PERKINS, Chris; DODGE, Martin. Thinking about maps. In: _ (eds) Rethinking Maps. Routledge, 2009. Cap. 1, p. 1-25. Disponível em <http://makingmaps.net $>$. Acesso em: jan. 2011.

MASSEY, Doreen. Pelo Espaço: uma nova política da espacialidade. Rio de Janeiro: Bertrand, 2008. 312 p. OLIVEIRA JR., Wenceslao Machado de. Apontamentos sobre a educação visual dos mapas: a (des)natureza da ideia de representação In: COLÓQUIO DE CARTOGRAFIA PARA CRIANÇAS E ESCOLARES, 6., 2009, Juiz de Fora. Anais... Juiz de Fora: UFJF, 2009. CD-ROM.

ROLNIK, Sueli. Cartografia sentimental: transformações contemporâneas do desejo. Porto Alegre: Sulina; Editora da UFRGS, 2007. 247 p.

Trabalho enviado em agosto de 2011

Trabalho aceito em outubro de 2011 